\title{
ERRATUM TO \\ "ON A CONJECTURE OF KOIKE ON IDENTITIES BETWEEN THOMPSON SERIES AND ROGERS-RAMANUJAN FUNCTIONS"
}

\author{
KATHRIN BRINGMANN AND HOLLY SWISHER \\ (Communicated by Ken Ono)
}

Abstract. This note gives a correction to formula (A.18) of Appendix A.

The correct formula in (A.18) should read

$u_{54,1}(z) u_{27,2}(z)=T_{54+}+1=e^{\frac{-\pi i}{6}} \cdot \frac{\eta(z+1 / 3) \eta(2 z+1 / 3) \eta(3 z+2 / 3) \eta(6 z+2 / 3)}{\eta(3 z) \eta(6 z) \eta(9 z) \eta(18 z)}+e^{\frac{2 \pi i}{6}}$.

\section{ACKNOWLEDGMENTS}

The authors would like to thank Michael Somos for pointing out the error in the original statement of this formula and for many helpful private communications.

\section{REFERENCES}

[1] K. Bringmann and H. Swisher, On a conjecture of Koike on indentities between Thompson series and Rogers-Ramanujan functions, Proc. Amer. Math. Soc., 135 (2007), 2317-2326. MR2302552

School of Mathematics, University of Minnesota, Minneapolis, Minnesota 55455

E-mail address: bringman@math.umn.edu

Department of Mathematics, Oregon State University, Corvallis, Oregon 97333

E-mail address: swisherh@math.oregonstate.edu

Received by the editors January 31, 2006 and, in revised form, March 27, 2006.

2000 Mathematics Subject Classification. 11F22, 33D15, $11 \mathrm{~F} 03$. 